Souchay, G., O. Gimenez, G. Gauthier, and R. Pradel. 2014. Variations in band reporting rate and implications for kill rate in Greater Snow Geese. Avian Conservation and Ecology 9(1): 1. http://dx.doi.org/10.5751/ACE-00628-090101

Copyright (C) 2014 by the author(s). Published here under license by the Resilience Alliance.

Research Paper

\title{
Variations in band reporting rate and implications for kill rate in Greater Snow Geese
}

Guillaume Souchay ${ }^{1,2}$, Olivier Gimenez ${ }^{2}$, Gilles Gauthier ${ }^{1}$ and Roger Pradel ${ }^{2}$

${ }^{1}$ Département de Biologie \& Centre d'Études Nordiques, ${ }^{2}$ Centre d'Écologie Fonctionnelle et Évolutive - UMR 5175

\begin{abstract}
We assessed spatial and temporal variation in reporting probability of banded Greater Snow Geese (Chen caerulescens atlantica) shot by hunters in eastern North America and evaluated potential residual biases in kill rate estimation. Adult Greater Snow Geese were marked with reward (value: US\$10, \$20, \$30, \$50, and \$100) and standard bands (\$0, control) in the Canadian Arctic from 2003 to 2005 . We used a spatially explicit multinomial model based on 200 direct recoveries from 4256 banded geese to estimate reporting rate and harvest rate. We found that reporting rate for standard bands varied over time whereas harvest rate was higher in Canada than in the U.S. The reporting probability increased from $0.40 \pm 0.11$ in the first year of the study to $0.82 \pm 0.14$ and $0.84 \pm 0.13$ the second and third years, respectively. Overall, these reporting rates are higher than two previous estimates for this population, which leads to lower estimates of kill rate. However, the large annual differences in reporting rates found in this study lead to uncertainty in the estimation of kill rate. We suggest that the increase in reporting rate in the last two year of the study may be due to the dissemination of information among hunters regarding the presence of reward bands on birds, resulting in increased reporting rate for all bands. This raises issues about the need to adequately inform the public in such large-scale studies to avoid undesirable temporal trends over the course of the study.
\end{abstract}

\section{Variations du taux de retour de bagues et répercussions sur le taux de récolte chez la Grande Oie des neiges.}

RÉSUMÉ. Nous avons déterminé la variabilité spatiale et temporelle de la probabilité de retourner des bagues de Grandes Oies des neiges (Chen caerulescens atlantica) récoltées par les chasseurs dans l'Est de l'Amérique du Nord, et évalué les biais inhérents potentiels dans l'estimation du taux de récolte. Les oies adultes ont été marquées à l'aide de bagues récompense (d'une valeur de 10, 20, 30, 50 ou 100 \$ US) et standards ( 0 \$ US, témoin) dans l'Arctique canadien de 2003 à 2005. Afin d'estimer le taux de retour de bagues par les chasseurs et le taux de récolte, nous avons utilisé un modèle multinomial spatialement explicite fondé sur 200 récupérations directes de bagues provenant d'un ensemble de 4256 oies baguées. Nos résultats indiquent que le taux de retour par les chasseurs pour les bagues standards a varié au cours du temps, tandis que le taux de récolte était plus élevé au Canada qu'aux États-Unis. La probabilité de retour de bagues par les chasseurs a augmenté de $0,40 \pm 0,11$ la première année de l'étude à $0,82 \pm 0,14$ et $0,84 \pm 0,13$ les deuxième et troisième années, respectivement. Ces taux de retour de bagues sont supérieurs à ceux estimés précédemment pour cette population, entrainant des estimations du taux de récolte plus faibles. Toutefois, la forte variation interannuelle dans les taux de retour de bagues par les chasseurs observée dans la présente étude engendre une grande incertitude pour l'estimation du taux de récolte. Nous suggérons que l'augmentation du taux de retour de bagues observée au cours des deux dernières années de notre étude pourrait être attribuable à la dissémination de l'information au sein des chasseurs quant à l'existence de bagues récompense sur les oiseaux, conduisant ainsi à une augmentation du taux de retour pour tout type de bagues. Cette étude souligne l'importance des informations à transmettre au public lors d'études à grande échelle afin d'éviter des tendances temporelles indésirables au cours de celles-ci.

Key Words: Atlantic Flyway; band recovery; Greater Snow Goose; kill rate; reporting rate; reward band; spatial variation; temporal variation; waterfowl

\section{INTRODUCTION}

An accurate estimation of harvest rate, the proportion of the population killed and retrieved by sport hunters, is critical for the management of most hunted populations (Williams et al. 2002). For instance, within the framework of adaptive harvest management used by the U.S. Fish and Wildlife Service (FWS), annual harvest rates are used to update annual hunting regulations of several waterfowl populations (Williams et al. 2002, Baldassarre and Bolen 2006). For several species, estimates of the absolute numbers harvested are obtained through an annual hunter survey, i.e., questionnaires sent to a sample of randomly selected hunters in which they reported the number of birds killed and retrieved (Baldassarre and Bolen 2006, Padding and Royle 2012). These values can then be converted into rates using population size estimates.

An alternative method to estimate harvest rate relies on direct recoveries of banded birds (Baldassarre and Bolen 2006). Newly banded birds can be re-encountered when shot and retrieved during the following hunting season, i.e., direct recoveries. In 
hunted species, most reported bands are reported by hunters, e.g., > $97 \%$ in the Greater Snow Goose (Chen caerulescens atlantica), and thus other kinds of recoveries can be neglected. However, because all banded birds that are killed and retrieved are not reported to the Bird Banding Laboratory (BBL), the recovery rate, defined as the probability that a bird will be shot, retrieved by a hunter, and reported to the BBL, is a biased estimation of harvest rate $(h)$. Estimating reporting rate $(\lambda)$, i.e., the probability that the band of a shot and retrieved bird is reported to the BBL, is thus critical to assess hunting mortality of managed populations (Padding and Royle 2012).

Reward band studies are typically used to estimate reporting rate (Nichols et al. 1991, 1995, Royle and Garrettson 2005, Zimmerman et al. 2009a, Boomer et al. 2013). This method allows the estimation of harvest probability $(h)$ separately from reporting $(\lambda)$ probability (Henny and Burnham 1976), based on the assumption that a reward value is high enough to obtain a reporting rate approximating 1.0 (Conroy and Williams 1981, Nichols et al. 1991, Royle and Garrettson 2005). A bird that carries the highest reward will be recovered with probability $h$ whereas a standard-banded bird will be recovered with probability $h \times \lambda$. These two parameters can thus be estimated separately. Multivalued reward band studies also enable a test of the assumption that the highest reward value is sufficient to ensure that the asymptotic reporting rate (assumed to be 1) is reached. This can be verified by regressing reporting probability on reward value (Royle and Garrettson 2005).

Previous studies have examined reporting probabilities in duck and goose populations across North America (Nichols et al. 1991, 1995, Royle and Garrettson 2005, Zimmerman et al. 2009a, Boomer et al. 2013). Zimmerman et al. (2009a) examined the reporting probability in 12 populations of 4 goose species (Canada Geese Branta canadensis, Cackling Geese B. hutchinsii, Snow Geese Chen caerulescens, and Ross's Geese C. rossii) after introduction in the mid-1990s of the toll-free phone number to report banded birds that are shot. They assessed variation in reporting probabilities among species, populations and harvest locations. In particular, they found spatial variation in reporting probability depending on the harvesting area, with lower reporting probabilities in Canada compared with the U.S.

Our objectives were to study geographical and temporal variation in reporting probability by Greater Snow Goose hunters in eastern North America. This goose population is unique in two ways, namely that harvest is equal or higher in Canada than in the U.S. (Calvert and Gauthier 2005), unlike most other waterfowl populations, and Canadian hunting occurs almost exclusively in Québec, the predominantly French-speaking province of Canada. Anecdotal observations (G. Gauthier, personal observation) suggested that cultural or linguistic differences could lead to differences in reporting rates between Québec and the U.S. (see also Zimmerman et al. 2009a, Boomer et al. 2013). Our analysis was based on a three-year reward band study conducted in Greater Snow Geese from 2003 to 2005, a subset of the large-scale study analyzed by Zimmerman et al. (2009a). Based on the results of previous reward-band studies conducted on ducks and geese in North America, we expected no temporal variation in the reporting probability over our study period but a higher reporting probability in northeastern United States than in Québec.

\section{METHODS}

\section{Field methods}

Greater Snow Geese were marked at the end of the summer on their arctic breeding ground at the Bylot Island, Nunavut, Canada $\left(73^{\circ}\right.$ $\mathrm{N}, 80^{\circ} \mathrm{W}$ ) colony from 1990 to 2010 (see Gauthier et al. 2001 for details). Goose families were captured during a 10-day period, when adults were molting and before young could fly. Birds were aged (young of the year or adult $\geq 1$ year-old) and all were banded with standard United States Geological Survey (USGS) bands. From 2003 to 2005, reward bands were applied to adults only. Controlbanded birds, both males and females, received the standard USGS band inscribed with a unique nine-digit number and "CALL 1-800-327-BAND, WRITE BIRD BAND LAUREL MD 20708 USA." Reward-banded geese were marked with the same standard band on one leg and with an additional band inscribed with "REWARD \$XXX" and a unique six-digit number on the other leg. Reward bands were manufactured to the same specifications as standard bands and were not permanently colored, unlike similar reward band programs in ducks (bands were only temporarily marked with a water-soluble, nontoxic green dye to aid in banding logistic). Bands of each type were alternatively applied in a 1:1 ratio ( $N=2139$ control-banded geese and $N=2117$ reward-banded geese, Table 1) and no other markers were used on the birds. Reward bands were divided into five values (US\$10, \$20, \$30, \$50, and \$100) and were equally distributed within the banded sample.

Table 1. Number of banded birds (N), number of direct recoveries (n), and direct recovery rates (f) of Greater Snow Geese (Chen caerulescens atlantica) marked at Bylot Island from 2003 to 2005 for each dollar value (x) of reward bands.

\begin{tabular}{cccc}
\hline \hline \$ Value $(x)$ & $N_{x}$ & $n_{x}$ & $f_{x}$ \\
\hline 0 & 2139 & 79 & 0.038 \\
10 & 425 & 18 & 0.042 \\
20 & 420 & 23 & 0.057 \\
30 & 425 & 32 & 0.075 \\
50 & 425 & 23 & 0.061 \\
100 & 422 & 26 & 0.064 \\
\hline
\end{tabular}

\section{Data analysis}

As typically done when estimating reporting rate and harvest rate (e.g., Zimmerman et al. 2009a), we only used direct recoveries, i.e., bands of birds shot or found dead by hunters and reported to the BBL during the first hunting season following banding $(n=200$ in total). A summary of the number of banded and recovered individuals by dollar value, year, and harvest area is available in Appendix 1. Although some birds may die before they reach areas exposed to hunting, i.e., during the fall migration from the Arctic to southern staging areas, survival during this period is very high $(\sim 0.98)$ and shows little annual variation (Gauthier et al. 2001).

Methods used to estimate reporting-rates of standard bands require the major assumption that $100 \%$ of the reward bands found with the highest dollar value are reported, otherwise estimates of reporting rates will be biased (Conroy and Williams 1981). Thus, our first objective was to assess the validity of the assumption that the reporting rate $(\lambda)$ had reached an asymptotic value for $\$ 100$ reward bands. The direct recovery rate of bands with dollar value 
$x$ was estimated as the ratio of direct recoveries $n_{x}$ to the number of bandings $N_{x}$ of dollar value $x\left(f=n_{x} / \mathrm{N}_{x}\right)$. Following Royle and Garrettson (2005), we assumed a binomial distribution for direct recoveries with recovery probability equal to the product of dollar-value specific reporting rate $(\lambda)$ and harvest rate $(h)$ :

$$
n_{x} \sim \operatorname{Bin}\left(N_{x}, \lambda_{x} \times h\right)
$$

We used a generalized linear model to evaluate the effect of dollar value on band reporting rate using a logit link:

$$
\operatorname{logit}\left(\lambda_{x}\right)=\alpha+\beta \times x
$$

where $\alpha$ and $\beta$ are the estimated parameters, and represent, respectively, the logit reporting rate for bands with $\mathrm{x}=0$, and the change in expected logit reporting rate per dollar in reward band value. This parametrization makes the implicit assumption that for sufficiently large dollar values, the band reporting rate is 1 . We used the function $n l m$ in the software $\mathrm{R}$ (R Development Core Team 2010) to perform this analysis. To evaluate whether the model fit the data, we evaluated goodness-of-fit using a chisquared statistic based on the expected recoveries $e_{x}$. Under the null hypothesis that the model provides a good fit to the data, the statistic

$$
\sum_{x} \frac{\left(j_{x}-e_{x}\right)^{2}}{e_{x}}
$$

has a $\chi^{2}$ distribution with $(j-k)$ degrees of freedom, where $j$ is the number of categories of observed recoveries and $k$ is the number of estimated parameters. The observed reporting rate for each dollar value may alternatively be estimated assuming $\lambda_{100}=$ 1. The observed reporting rate for bands of dollar value $x$ is then

$$
\hat{\lambda}_{x}=\hat{f}_{x} / \hat{f}_{\$ 100}
$$

(Royle and Garrettson 2005).

In a second step, we tested temporal and regional effects on reporting rate. We started by estimating annual reporting $(\lambda)$ and harvest $(h)$ rates of Greater Snow Geese in two different geographical areas, Québec and U.S., from direct recoveries. Following Nichols et al. (1995), the harvest rate represents the probability that an individual is harvested in a particular recovery unit (Québec or USA). Because of potential band loss, we introduced a band retention probability $(\theta=0.9995)$ estimated by Zimmerman et al. $(2009 b)$. We assumed that the vector of band recoveries in Québec and USA was distributed as:

$$
\operatorname{Multiniomal}\left(N_{t}, \theta \times h_{i t} \times \lambda_{i x t}\right)
$$

where $N_{t}$ is the number of individuals banded and released just before hunting season $t$ from the Greater Snow Goose population, $h_{i t}$ is the harvest rate, i.e., the probability that a bird is harvested in spatial area $i$ in hunting season $t$, and $\lambda_{i x t}$ is the reporting probability for geese recovered in spatial area $i$ with dollar value $x$ in hunting season $t$. We considered a linear logistic model relating reporting rate to dollar value $x$, analogous to Equation 2:

$$
\operatorname{logit}\left(\lambda_{i x t}\right)=\log \left(\frac{\lambda_{i x t}}{1-\lambda_{i x t}}\right)=\alpha^{\prime}+\beta^{\prime}{ }_{i x t}
$$

where $\alpha$ ' and $\beta$ ' are regression parameters to be estimated. From Equation 5, it can be seen that the intercept $\alpha$ ' is the reporting rate for band with $x=0$, i.e., standard band. Because of the sparseness of the data once dividing recoveries into distinct spatial and time units, we assumed that $\$ 100$ reward bands were reported with a probability of 1.0 and fixed $\lambda_{i, \$ 100, t}=1$. This assumption was supported by previous works on waterfowl (Zimmerman et al., $2009 a$ ) and our own results.

We adopted a Bayesian approach using Markov Chain Monte Carlo (MCMC) simulations to implement all models. We specified the model to run in the form of the likelihood and noninformative prior distributions for all parameters to be estimated. We used empirical means and standard deviations to summarize these posterior parameter distributions (Gimenez et al. 2009, 2012). For priors, we used a Normal distribution $(0,10)$ for $\alpha$, a Normal distribution $(0,100)$ for $\beta$, and a Uniform distribution $(0,1)$ for $h$. We used program JAGS (Plummer 2003) called from R (R Development Core Team 2010). We ran 200,000 iterations including 100,000 burn-in. We also tested reduced models where reporting and harvest rates did not vary according to time and/or area of recovery. All these models could be compared to each other because they were based on the same dataset. Model selection was conducted using the Deviance Information Criterion (DIC; Spiegelhalter et al. 2002). The code is available in Appendix 2.

In a final step, we applied the estimation of reporting rate $\lambda$ obtained in the Bayesian analysis to $f$ values obtained from an independent band recovery analysis to estimate the probability of being killed by a hunter or kill rate $(K)$. This probability must account for the proportion of birds that are shot by hunters but not retrieved because the harvest rate is based solely on retrieved birds (Anderson and Burnham 1976). Thus, we estimated $K$ as follows:

$$
K=\frac{f}{c \times \lambda}
$$

where $c$ the retrieval rate, i.e., the probability that a hunter retrieves a shot bird. We used a constant value of 0.80 for retrieval rate from Henny and Burnham (1976) because this is the only available estimate for this parameter. Values of $f$ came from a standard, annual band recovery analysis that included both adults and young for the later period of the banding study (2002 to 2010, results of this analysis are given in Appendix 3). We used the same procedure as Calvert and Gauthier (2005) except that we did not include birds that received a neck band during this period. To obtain the standard error of the estimated kill rate, we used the delta-method (Seber 1982).

\section{RESULTS}

Overall, direct recovery rates $(f)$ was 0.037 in control birds and ranged from 0.042 to 0.075 for reward-banded birds with different dollar values (Table 1). The band reporting rate based on our binomial model increased rapidly with dollar value. The estimated reporting rate function 


$$
\operatorname{logit}\left(\lambda_{x}\right)=0.3207+0.0910 x
$$

showed a reasonable fit with the observed reporting rate for each dollar value (Fig. 1). The predicted reporting rate was equal to 1.0 (horizontal line on the figure) at a dollar value around $\$ 60$, although point estimate at a value of $\$ 30$ was $>1.0$ (Fig.1). Based on parameters of the fitted model, the expected number of recoveries for each dollar value were 78.0, 20.7, 23.6, 25.5, 26.5, and 26.6 for $x=0,10,20,30,50$, and $\$ 100$, respectively. Our goodness-of-fit test $\left(\chi^{2}[3]=2.50, P=0.475\right)$ suggested no lackof-fit.

Fig. 1. Moment estimates of reward band reporting rate $\left(\lambda_{x}\right)$ of Greater Snow Geese (Chen caerulescens atlantica) banded from 2003 to 2005 . Each observed reward-band reporting rate was obtained assuming that $\lambda_{100}=1$. The curve is the fitted reporting rate function $\left(\operatorname{logit}\left[\lambda_{\mathrm{x}}\right]=0.3207+0.0910 \mathrm{x}\right)$ and the horizontal dotted line is $\lambda=1.0$.

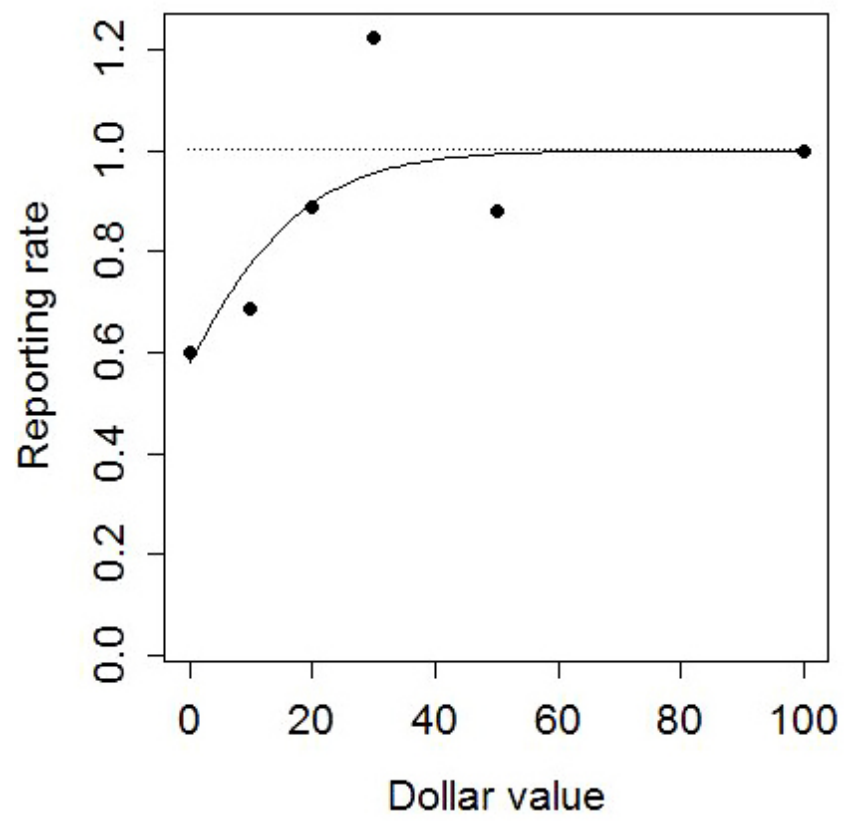

In our evaluation of temporal and spatial effects on reporting rate, the top-ranked model retained both of these effects in interaction (Table 2). Whereas adding the year effect on reporting rate greatly improved the fit compared to the constant model, region improved the fit only when added in combination with year. Moreover, because a model without a region effect on reporting rate fitted the data almost as well as one with such an effect (M3 vs. M4, Table 2) and was more parsimonious, we based our interpretation on the model with only a year effect. Reporting rate of birds with standard USGS bands only was very similar in 2004 and 2005 but was only half of those values in the first year of the study (2003; Model M3, Table 3). We further note that the interaction with region in the more complex model (M4) was mostly due to the very low reporting rate in the USA compared to Québec in the first year of the study $(0.24 \pm 0.13$ [SE] and 0.56 \pm 0.18 , respectively). However, we recognize that point estimates were based on relatively small sample size when broken down by region and years (Appendix 1). Finally, our two top-ranked models included only spatial effect on the harvest rate with no time-dependent effects (models with a year effect on harvest rate had a $\triangle \mathrm{DIC}>3$; Table 2). Harvest rates estimates were higher for Québec $(0.034 \pm 0.004)$ than for the USA $(0.023 \pm 0.003)$, as expected.

Table 2. Model selection for the effects of year (2003 to 2005) and geographic region (Québec vs U.S.) on Greater Snow Goose (Chen caerulescens atlantica) harvest and band reporting rates by hunters. All models include a linear effect (logit scale) of U.S. dollar value on reporting rate. Mean deviance (D), effective number of parameters $\left(p_{D}\right)$, and difference in deviance information criterion $(\triangle \mathrm{DIC})$ are given. Models are sorted by $\triangle \mathrm{DIC}$ with respect to the best model.

\begin{tabular}{|c|c|c|c|c|c|}
\hline \multirow[t]{2}{*}{$\#$} & \multicolumn{2}{|c|}{ Effect on } & \multirow[t]{2}{*}{$\mathrm{D}$} & \multirow{2}{*}{$p_{D}$} & \multirow[t]{2}{*}{$\Delta \mathrm{DIC}$} \\
\hline & $h$ & $\lambda$ & & & \\
\hline M4 & Region & $\begin{array}{l}\text { Region* } \\
\text { Year }\end{array}$ & 153.4 & 7.2 & 0.0 \\
\hline M3 & Region & Year & 156.0 & 4.8 & 0.2 \\
\hline M8 & $\begin{array}{l}\text { Region* } \\
\text { Year }\end{array}$ & Constant & 156.4 & 7.2 & 3.0 \\
\hline M7 & $\begin{array}{l}\text { Region* } \\
\text { Year }\end{array}$ & Year & 155.9 & 9.3 & 4.6 \\
\hline M1 & Region & Constant & 162.2 & 3.1 & 4.7 \\
\hline M5 & $\begin{array}{l}\text { Region* } \\
\text { Year }\end{array}$ & Region & 157.3 & 8.3 & 5.0 \\
\hline M6 & $\begin{array}{l}\text { Region* } \\
\text { Year }\end{array}$ & $\begin{array}{l}\text { Region* } \\
\text { Year }\end{array}$ & 154.6 & 11.5 & 5.5 \\
\hline M2 & Region & Region & 163.3 & 4.2 & 6.9 \\
\hline
\end{tabular}

We estimated kill rate for the period of the reward-band study (2003-2005) using the various point estimates of $\lambda$ obtained in models M1 to M4 (Table 3) to examine the sensitivity of this parameter to reporting rate. We added estimation of kill rate from other studies using reporting rate values calculated by Calvert and Gauthier (2005) and Zimmerman et al. (2009a). Finally, we calculated an independent estimate of kill rate based on the ratio of the number of geese reported to be shot in hunter questionnaire survey and the population size at the start of the hunting season (see Gauthier et al. 2001 for details; this estimate was also corrected for retrieval rate). We found that kill rate estimated based on the three time-independent reporting rates (constant over region and region-specific) were similar (Fig. 2). Theses kill rates were generally lower than kill rates estimated based on reporting rate from Calvert and Gauthier (2005) and Zimmerman et al. ( $2009 a ; \lambda=0.36$ and 0.52 in those studies, respectively) and also slightly lower than kill rates based on the hunter survey. Kill rates estimated with temporal-dependent reporting rate were higher than kill rate based on our constant reporting rate for 2003 and lower for 2004 and 2005 (Fig. 2).

Finally, we examined how using various estimates of reporting rate could have affected our evaluation of temporal trends in kill rates of Greater Snow Geese over the period 2002-2010 (Fig. 3). For both juvenile and adult, kill rates estimated using our constant reporting rate value were the lowest. Kill rates based on Zimmerman et al. (2009a) and Calvert and Gauthier (2005) reporting rates were $24 \%$ and $70 \%$ higher, respectively, than based on our estimate. 
Table 3. Point estimates of reporting rate of Greater Snow Geese (Chen caerulescens atlantica) with standard metal band, i.e., \$0 value, from the models M1 to M4 in Table 2, where the harvest rate is only region-dependent. QC = Québec.

\begin{tabular}{cccccc}
\hline \hline$\#$ & Effects on & Region & Year & $\lambda($ SE) & {$[95 \%$ quantiles $]$} \\
\cline { 2 - 5 } & $\lambda$ & & & & \\
\hline M1 & Constant & - & - & $0.65(0.10)$ & {$[0.48-0.87]$} \\
M2 & Region & QC & - & $0.65(0.13)$ & {$[0.42-0.94]$} \\
& & U.S. & - & $0.75(0.17)$ & {$[0.46-0.99]$} \\
M3 & Year & - & 2003 & $0.40(0.11)$ & {$[0.23-0.65]$} \\
& & - & 2004 & $0.82(0.13)$ & {$[0.54-0.99]$} \\
& & - & 2005 & $0.84(0.13)$ & {$[0.56-0.99]$} \\
M4 Region*Year & QC & 2003 & $0.56(0.18)$ & {$[0.27-0.97]$} \\
& & QC & 2004 & $0.66(0.19)$ & {$[0.33-0.99]$} \\
& & QC & 2005 & $0.84(0.14)$ & {$[0.51-0.99]$} \\
& & U.S. & 2003 & $0.24(0.13)$ & {$[0.07-0.57]$} \\
& & U.S. & 2004 & $0.90(0.11)$ & {$[0.61-0.99]$} \\
& & U.S. & 2005 & $0.82(0.16)$ & {$[0.45-0.99]$} \\
\hline
\end{tabular}

Fig. 2. Estimated Kill rate $( \pm S E)$ for each year of the reward band study using various point estimates of reporting rate $(\lambda)$ from models M1 to M4 in Table 4 or from two other studies (Calvert and Gauthier 2005 and Zimmerman et al. 2009a) and a uniform value for retrieval rate (0.8; see methods). Qc = Québec.

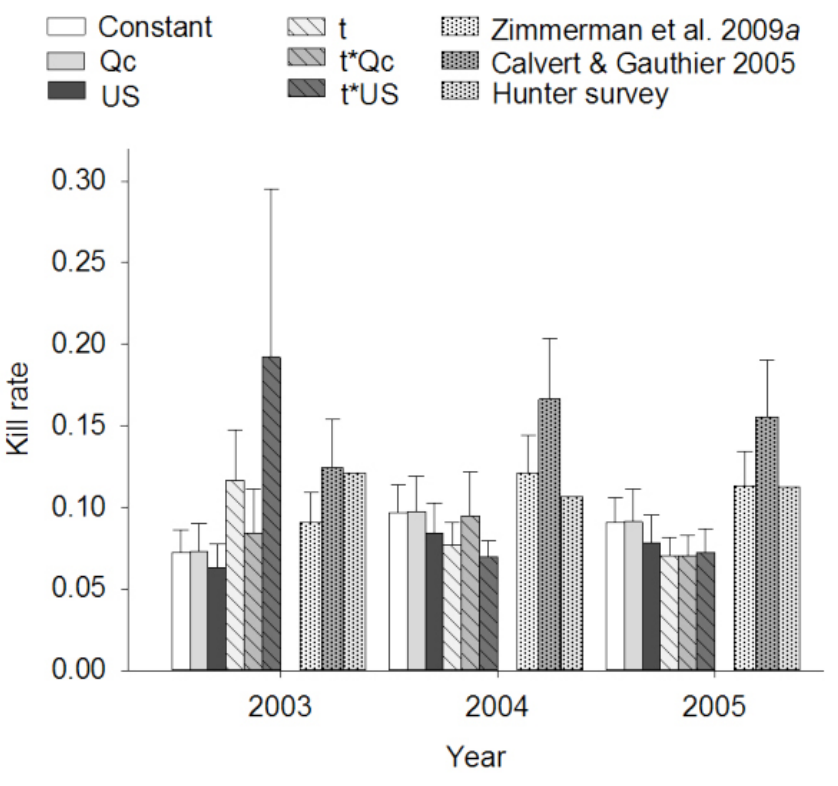

\section{DISCUSSION}

Our study provided strong evidence for temporal variation in reporting rates in Greater Snow Geese over the course of the threeyear reward band study. However, evidence for variations in reporting rates between Québec and the U.S. were limited, and we found little support for the hypothesis of a lower reporting rate in Québec than in the U.S.
Fig. 3. Temporal trend in kill rates $( \pm S E)$ of juvenile and adult Greater Snow Geese (Chen caerulescens atlantica) banded from 2002 to 2010 using various point estimates of kill rate (value from constant model in Table 4, Calvert and Gauthier 2005 and Zimmerman et al. 2009a) based on annual recoveries obtained from a standard band recovery analysis and a uniform value of retrieval rate ( 0.8 ; see methods).

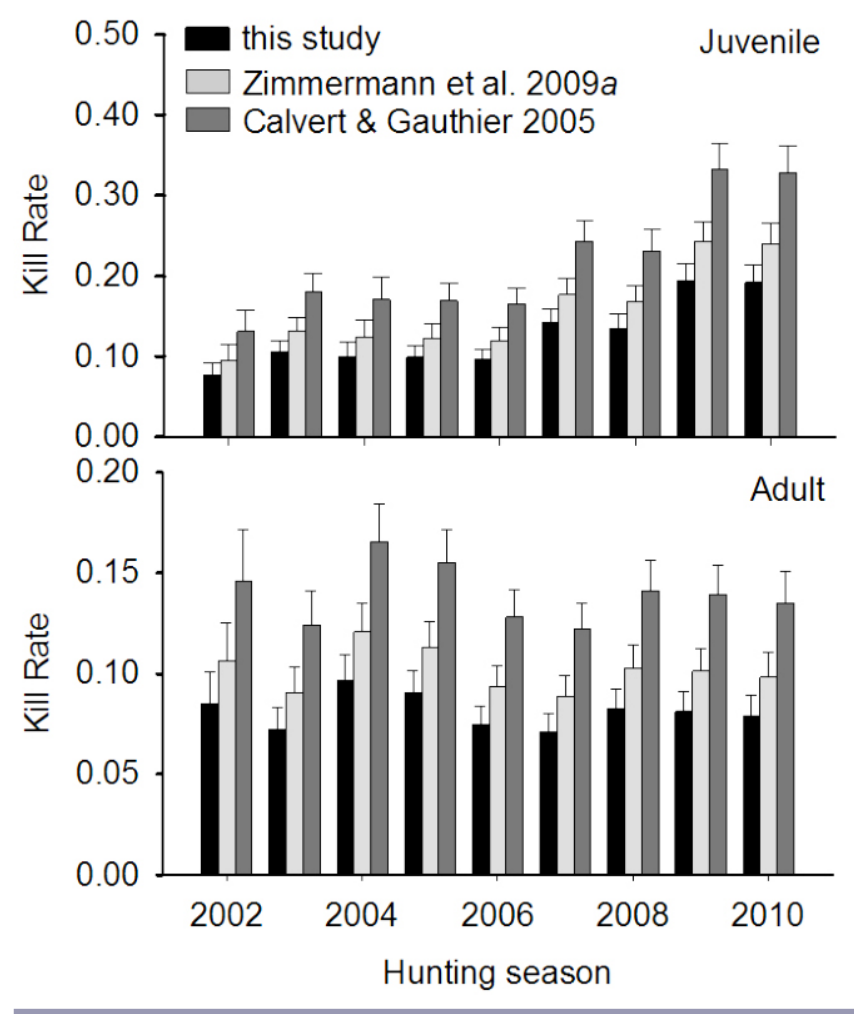

In an analysis combining both Canada Geese and Snow Geese, Zimmerman et al. (2009a) found lower reporting rate in Canada than in United States and lower in the Atlantic Flyway than in the nearby Mississippi Flyway. They suggested three explanations for these results. The first one was related to the dominance of French-speaking people in Québec, which may have created a language barrier to reporting reward bands with English-only inscriptions. A second explanation referred to the reluctance of hunters to report harvested Canada Geese because of hunting closures in the previous decade, thinking that reporting harvest could lead to another closure. Last, they suggested a lack of incentive to report nonreward bands by Canadians, because Canadians routinely receive financial rewards when reporting tagged fish. Our study, which concerned only the Greater Snow Goose, found little difference in reporting rates between the two countries with only a weak trend toward lower reporting rate in Canada. This suggests that the higher U.S. reporting rate found by Zimmerman et al. (2009a) was probably due more to the inclusion of Canada Geese in the dataset than to a language barrier between Québec and the eastern U.S. Contrary to Canada Geese in the Atlantic flyway, the Greater Snow Goose population is considered overabundant, and special measures have been implemented to increase harvest (Giroux et al. 1998, Reed and Calvert 2007). Therefore, hunters are not concerned with possible 
closure of their hunt and should have no issue in reporting their harvest in the U.S. or Canada. In a recent study of band reporting rate in Mallards (Anas platyrhynchos), Boomer et al. (2013) also found lower reporting rates in eastern Canada than in the eastern U.S., and also pointed out that linguistic differences could explain the lower reporting rate in Québec. A possible explanation for these apparently contradictory results could be that Snow Goose hunters differ from duck hunters, with probably a higher proportion of them using outfitters, which may be more aware of the importance of reporting bands.

Our most surprising finding is the strong evidence for temporal variation in reporting rate over the three-year reward-band study, which was not documented by Zimmerman et al. (2009a) for all goose populations at the continental scale. We note, however, that models that included a year effect on reporting rate were close competitors to models without this effect in their study $(\triangle \mathrm{AICc}$ $\leq 2.0$ between such models depending of the spatial scale; see Appendix B in Zimmerman et al. 2009a). The pattern in our study was for a much lower reporting rate in the first year than in the subsequent two years. We suggest that this pattern may be a consequence of the study design. No public information was provided to the hunting public in either country regarding the reward-band study before the beginning of the study to avoid a change in hunters' behavior. Hunters received information on this reward band program only when they reported one of the bands to the BBL (T. Moser, U.S. FWS, personal communication). However, after the first hunting season, the word presumably spread within the hunting community about the presence of birds with reward bands, likely aided by internet forums. Thus, increased awareness may have resulted in hunters paying more attention to the presence of bands on geese over time and may have motivated them to report them at a greater rate, even in the absence of a reward band. Confusion as to whether only some bands or all bands were subject to a reward may have been a factor also. We recognize that similar reward-band studies had been implemented on Mallards and Black Ducks (Anas rubripes) a year before the one on geese in eastern North America (see Boomer et al. 2013 on Mallard, and P. Garrettson, R. Raftovich, J. Hines, and G. Zimmerman unpublished data on both Mallards and Black Ducks). Nonetheless, we believe that the presence of rewardbands was still a novelty for hunters at the start of our study, especially considering that the population of Snow Goose hunters may differ somewhat from the one of duck hunters.

The presence of temporal variation in the estimation of reporting rate creates problems for the estimation of kill rate. If hunters indeed changed their attitude after the first year of this rewardband study and reported bands at a higher rate as we suggested, then the more realistic and least biased reporting rate should be the one associated with the first year of the study, $0.40 \pm 0.11$ in our case. We note that this estimation of reporting rate is similar to the one ( 0.36 to 0.40 ) of Calvert and Gauthier (2005) based on the relationship between band-recovery rate and harvest rate, independent of any reward-band study. However, because reward bands persist in the marked population for a few years and hunters remain aware of them, then a reporting rate close to $0.84 \pm 0.13$ may be more appropriate in the short term. We note that these differences are not trivial because they would result in a twofold difference in the estimation of kill rate. Kill rate estimates derived from the hunter survey were in the range of those estimated from band recovery analysis. However, because these estimates are also subject to potential biases (Calvert and Gauthier 2005, Padding and Royle 2012), they are not accurate enough to determine which band reporting rate estimate is most appropriate. Therefore, in the face of all those uncertainties, using the intermediate band reporting rate value provided by our constant model $(\lambda=0.65$ $\pm 0.10)$ may be the best alternative at the moment. This estimate is higher than the one from Zimmerman et al (2009a) for the same population $(0.52 \pm 0.09)$ but lower than their overall estimation for all geese across North America $(0.73 \pm 0.02)$. These results suggest that applying a common reporting rate to all goose populations may not be appropriate and that estimates based on population-specific analyses are preferable.

\section{Management implications}

Although reward-band studies are thought to produce less biased harvest rate estimates than those based on harvest surveys, e.g., Parts Collection Survey (Padding and Royle 2012), we found unexpected temporal variation associated with the estimation of reporting rate during a short-term reward-band study for one goose population. Thus, managers should be aware that using a constant reporting rate could introduce biases when estimating harvest rate from band recoveries. If our interpretation that the reporting rate may have been inflated in the recent reward-band study conducted in North America, then using such values would likely underestimate harvest once the "reward-band effect" is no longer present.

The increase in reporting rates after the first year of the rewardband study that we observed raises questions about what is the best public policy strategy to adopt when implementing such large scale programs. When no public information is released at the onset of the program, as was the case here, the spread of information or misinformation during the study could result in undesirable temporal changes in reporting rates over the period of the study, including for standard, nonreward bands. In contrast, a public information campaign at the start of such a program could make clear the distinction between a reward and a nonreward band. We recognize that publicizing a reward-band program could lead to increased harvest rate if hunters increased their activity in the hope of shooting a bird with a reward band. Nonetheless, we believe that a carefully designed public information campaign at the start of such a program may be desirable, especially if hunters are made aware of the low probability of shooting a bird with a reward-band.

Responses to this article can be read online at: http://www.ace-eco.org/issues/responses.php/628

\section{Acknowledgments:}

This study was funded by the Natural Sciences and Engineering Research Council of Canada, the Arctic Goose Joint Venture (Canadian Wildlife Service), the Centre d'Études Nordiques, the Department of Indian and Northern Affairs Canada, and the International Research Group Dynamics of Biodiversity and LifeHistory traits. Funding for the reward program (bands and rewards) was provided by the United States Geological Survey Bird Banding Laboratory. We especially thank T. J. Moser for managing the reward-band program and for valuable information about the program. P. Garrettson and A. Royle provided precious help to carry out the statistical analyses. We are grateful to the numerous field 
assistants that helped with goose banding and especially G. Picard, and to all the hunters who reported the banded birds that they shot. We thank M.-C. Cadieux for managing the database and for assistance in the field. We are grateful to two anonymous reviewers for their valuable comments to improve our earlier version of our manuscript.

\section{LITERATURE CITED}

Anderson, D. R., and K. P. Burnham. 1976. Population ecology of the mallard: VI. The effect of exploitation on survival. U.S. Fish and Wildlife Service Resource Publication 128, Washington, D.C., USA.

Baldassarre, G. A., and E. G. Bolen. 2006. Waterfowl ecology and management. Second edition. Krieger, Malabar, Florida, USA.

Boomer, G. S., G. S. Zimmerman, N. L. Zimpfer, P. R. Garrettson, M. D. Koneff, T. A. Sanders, K. D. Magruder, and J. A. Royle. 2013. Band reporting probabilities for mallards recovered in the United States and Canada. Journal of Wildlife Management 77:1059-1066. http://dx.doi.org/10.1002/jwmg.570

Calvert, A. M., and G. Gauthier. 2005. Effects of exceptional conservation measures on survival and seasonal hunting mortality in Greater Snow Geese. Journal of Applied Ecology 42:442-452. http://dx.doi.org/10.1111/j.1365-2664.2005.01042.x

Conroy, M. J., and B. K. Williams. 1981. Sensitivity of band reporting-rate estimates to violations of assumptions. Journal of Wildlife Management 45:789-792. http://dx.doi.org/10.2307/3808724

Gauthier, G., R. Pradel, S. Menu, and J.-D. Lebreton. 2001. Seasonal survival of Greater Snow Geese and effect of hunting under dependence in sighting probability. Ecology 82:3105-3119. http://dx.doi.org/10.1890/0012-9658(2001)082[3105:SSOGSG]2.0. $\mathrm{CO} ; 2$

Gimenez, O., S. J. Bonner, R. King, R. A. Parker, S. P. Brooks, L. E. Jamieson, V. Grosbois, B. J. T. Morgan, and L. Thomas. 2009. WinBUGS for population ecologists: Bayesian modeling using Markov chain Monte Carlo methods. Modeling Demographic Processes in Marked Populations 3:883-915.

Gimenez, O., J.-D. Lebreton, J.-M. Gaillard, R. Choquet, and R. Pradel. 2012. Estimating demographic parameters using hidden process dynamic models. Theoretical Population Biology 82:307-316. http://dx.doi.org/10.1016/j.tpb.2012.02.001

Giroux, J. F., B. Batt, S. Brault, G. Costanzo, B. Filion, G. Gauthier, D. Luszcz, and A. Reed. 1998. Conclusions and management recommendations. Pages 81-88 in B. Batt, editor. The Greater Snow Goose, report of the Arctic Goose Habitat Working Group. U.S. Fish and Wildlife Service, Washington, D.C., USA and Canadian Wildlife Service, Ottawa, Ontario, Canada.

Henny, C. J., and K. P. Burnham. 1976. A reward band study of Mallards to estimate band reporting rates. Journal of Wildlife Management 40:1-14. http://dx.doi.org/10.2307/3800150
Nichols, J. D., R. J. Blohm, R. E. Reynolds, R. E. Trost, J. E. Hines, and J. P. Bladen. 1991. Band reporting rates for Mallards with reward bands of different dollar values. Journal of Wildlife Management 55:119-126. http://dx.doi.org/10.2307/3809248

Nichols, J. D., R. E. Reynolds, R. J. Blohm, R. F. Trost, J. E. Hines, and J. P. Bladen. 1995. Geographic-variation in band reporting rates for Mallards based on reward banding. Journal of Wildlife Management 59:697-708. http://dx.doi.org/10.2307/3801946

Padding, P. I., and J. A. Royle. 2012. Assessment of bias in US waterfowl harvest estimates. Wildlife Research 39:336-342. http:// dx.doi.org/10.1071/WR11105

Plummer, M. 2003. JAGS: A program for analysis of Bayesian graphical models using Gibbs sampling. In K. Hornik, F. Leisch, and A. Zeileis, editors. Proceedings of the 3rd International Workshop on Distributed Statistical Computing (DSC 2003). Vienna University, Austria.

R Development Core Team. 2010. R: a language and environment for statistical computing. R Foundation for Statistical Computing, Vienna, Austria.

Reed, E. T., and A. M. Calvert. 2007. Evaluation of special conservation measures for Greater Snow Geese: report of the Greater Snow Goose working group. Arctic Goose Joint Venture Special Publication. Canadian Wildlife Service, Sainte-Foy, Québec, Canada.

Royle, J. A., and P. R. Garrettson. 2005. The effect of reward band value on mid-continent Mallard band reporting rates. Journal of Wildlife Management 69:800-804. http://dx.doi.org/10.2193/0022-541X (2005)069[0800:TEORBV]2.0.CO;2

Seber, G. A. F. 1982. The estimation of animal abundance and related parameters. Second edition. Chapman, London, UK and Macmillan, New York, New York, USA.

Spiegelhalter, D. J., N. G. Best, B. P. Carlin, and A. Van Der Linde. 2002. Bayesian measures of model complexity and fit. Journal of the Royal Statistical Society: Series B (Statistical Methodology) 64:583-639. http://dx.doi.org/10.1111/1467-9868.00353

Williams, B. K., J. D. Nichols, and M. J. Conroy. 2002. Analysis and management of animal populations. Academic, London, UK.

Zimmerman, G. S., W. L. Kendall, T. J. Moser, G. C. White, and P. F. Doherty. 2009b. Temporal patterns of apparent leg band retention in North American geese. Journal of Wildlife Management 73:82-88. http://dx.doi.org/10.2193/2007-590

Zimmerman, G. S., T. J. Moser, W. L. Kendall, P. F. Doherty, G. C. White, and D. F. Caswell. 2009a. Factors influencing reporting and harvest probabilities in North American geese. Journal of Wildlife Management 73:710-719. http://dx.doi.org/10.2193/2008-145
Editor-in-Chief: Keith A.Hobson Subject Editor: Thomas D.Nudds
Sponsored by the Society of Canadian Ornithologists and Bird Studies Canada Parrainée par la Société des ornithologistes $d u$ Canada et Etudes d'oiseaux Canada

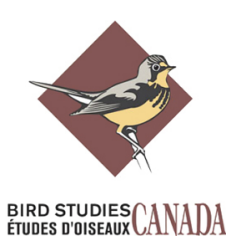


Appendix 1. Number of greater snow geese banded $(N)$ on Bylot Island and of direct recoveries $(n)$ according to dollar value of reward bands, year and geographic locations of recoveries from 2003 to 2005 .

\begin{tabular}{|c|c|c|c|c|}
\hline \multirow{2}{*}{ \$ VALUE } & \multirow[t]{2}{*}{ YEAR } & \multirow[t]{2}{*}{$N$} & \multicolumn{2}{|r|}{$n$} \\
\hline & & & QC & U.S.A \\
\hline \multirow[t]{4}{*}{0} & 2003 & 762 & 13 & 5 \\
\hline & 2004 & 665 & 13 & 16 \\
\hline & 2005 & 712 & 19 & 13 \\
\hline & TOTAL & 2139 & 45 & 34 \\
\hline \multirow[t]{4}{*}{10} & 2003 & 151 & 2 & 0 \\
\hline & 2004 & 133 & 5 & 4 \\
\hline & 2005 & 141 & 5 & 2 \\
\hline & TOTAL & 425 & 12 & 6 \\
\hline \multirow[t]{4}{*}{20} & 2003 & 147 & 3 & 3 \\
\hline & 2004 & 132 & 3 & 2 \\
\hline & 2005 & 141 & 6 & 6 \\
\hline & TOTAL & 420 & 12 & 11 \\
\hline \multirow[t]{4}{*}{30} & 2003 & 150 & 8 & 2 \\
\hline & 2004 & 133 & 6 & 5 \\
\hline & 2005 & 142 & 9 & 2 \\
\hline & TOTAL & 425 & 23 & 9 \\
\hline \multirow[t]{4}{*}{50} & 2003 & 151 & 4 & 6 \\
\hline & 2004 & 132 & 6 & 2 \\
\hline & 2005 & 142 & 4 & 1 \\
\hline & TOTAL & 425 & 14 & 9 \\
\hline \multirow[t]{4}{*}{100} & 2003 & 151 & 5 & 4 \\
\hline & 2004 & 131 & 3 & 5 \\
\hline & 2005 & 140 & 5 & 4 \\
\hline & Total & 422 & 13 & 13 \\
\hline
\end{tabular}


Appendix 2. R code for multinomial modelization.

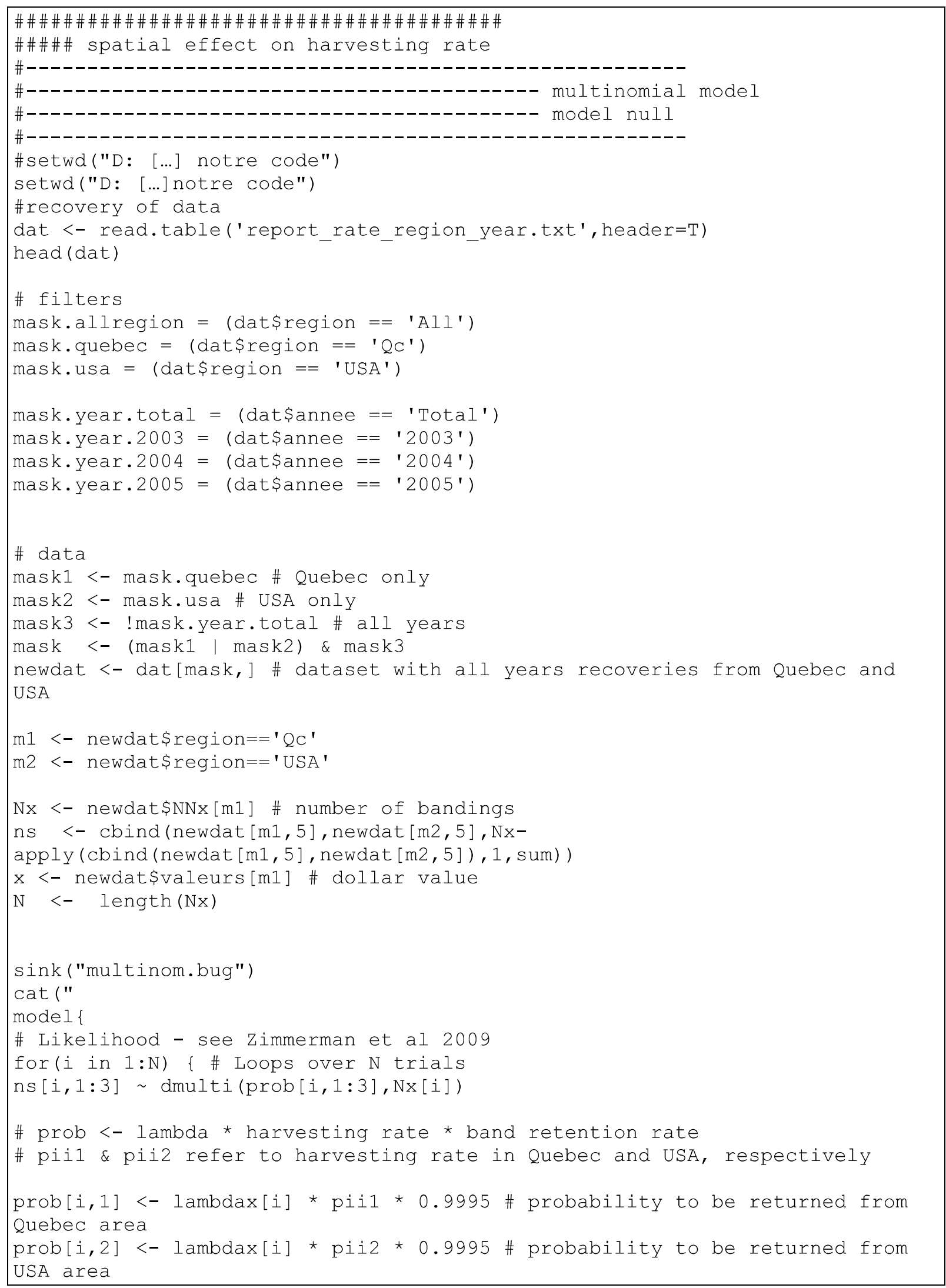




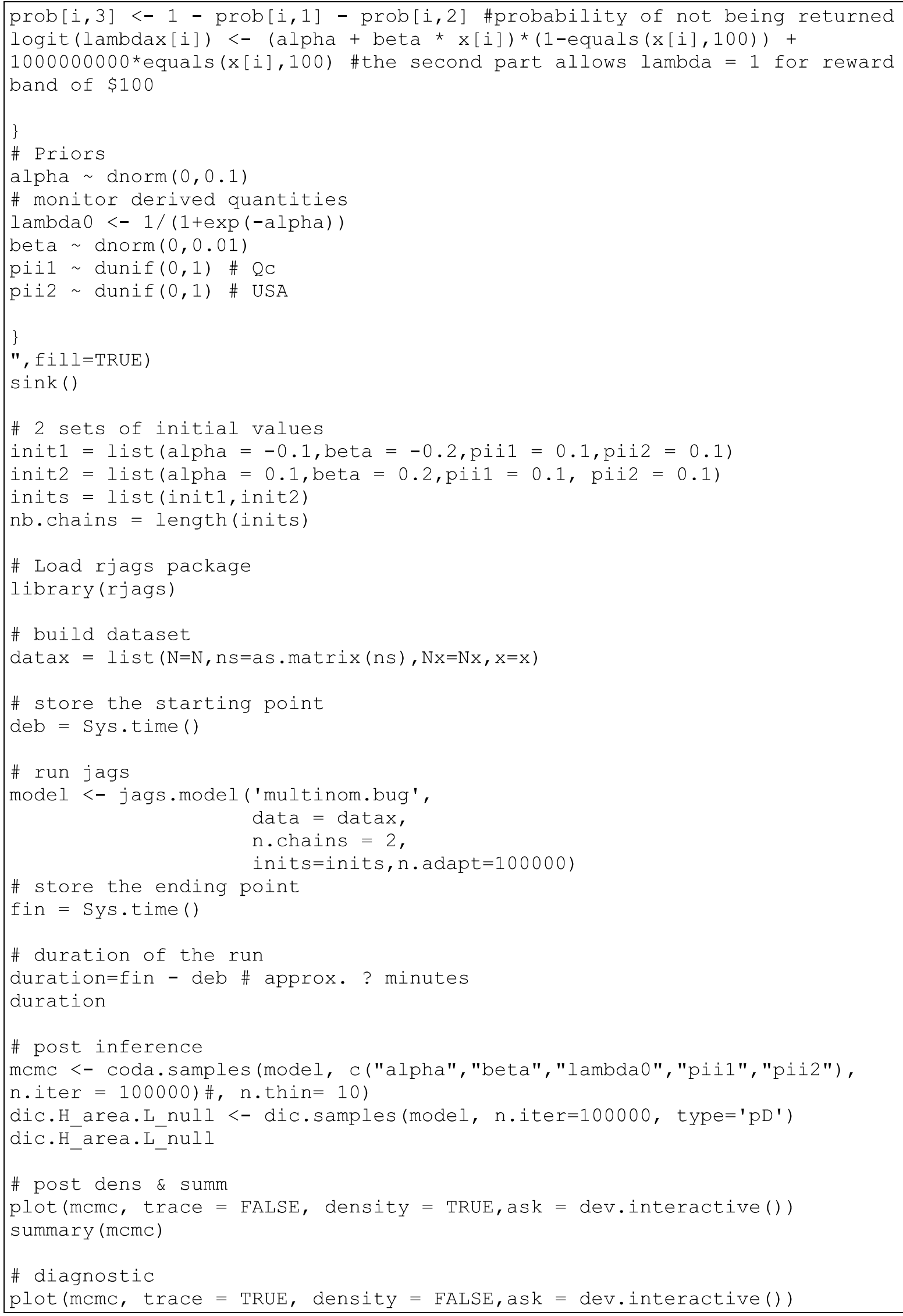




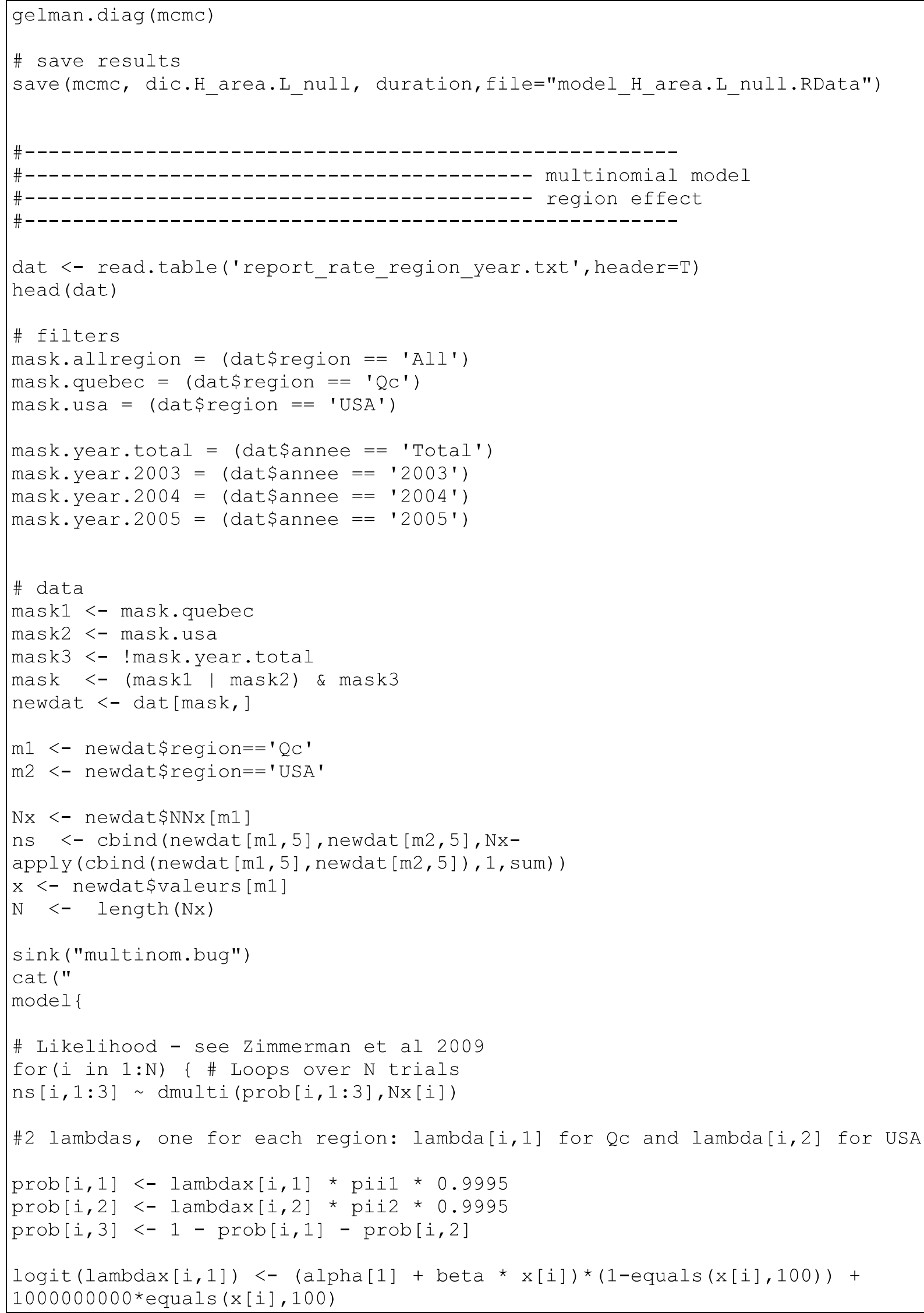




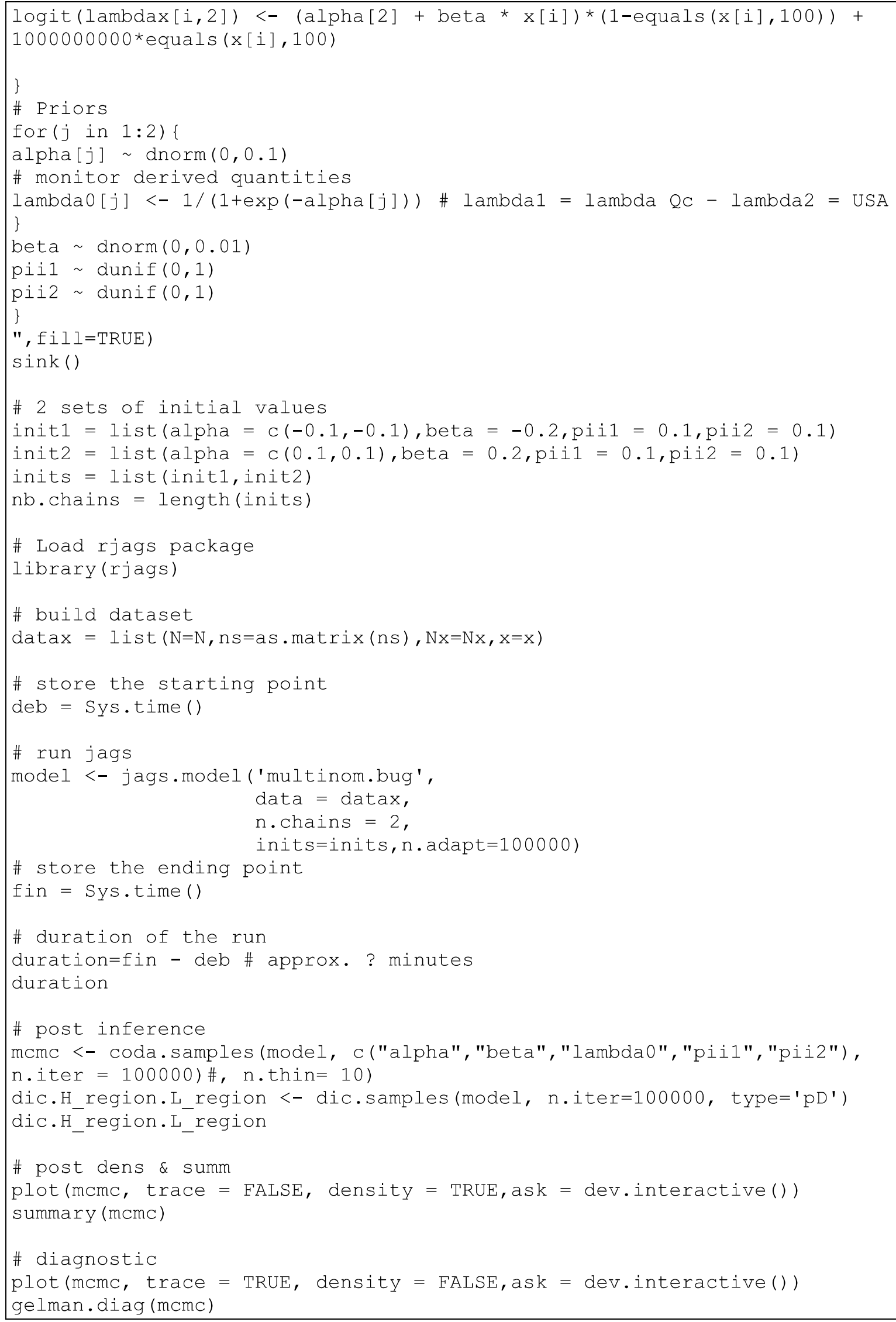




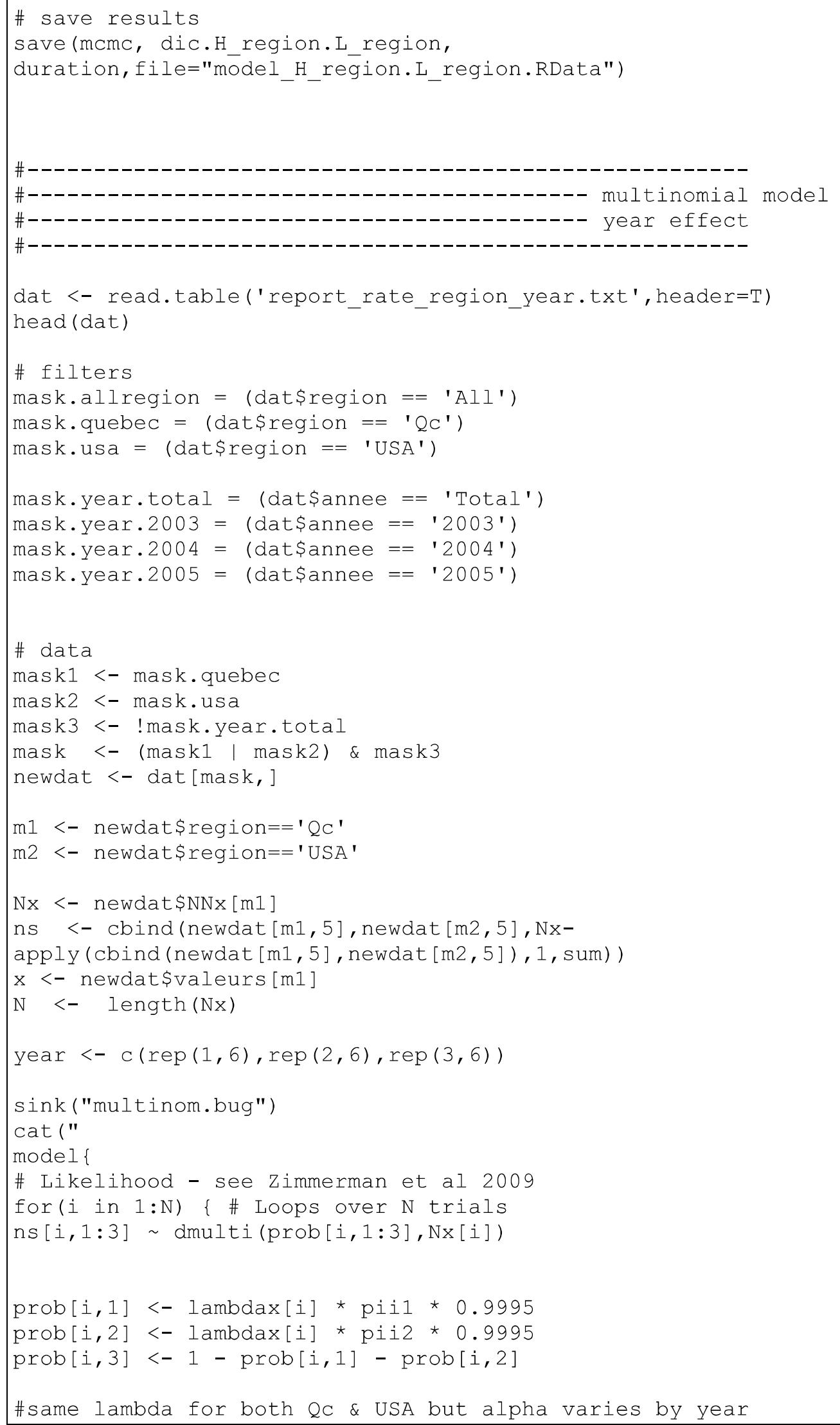




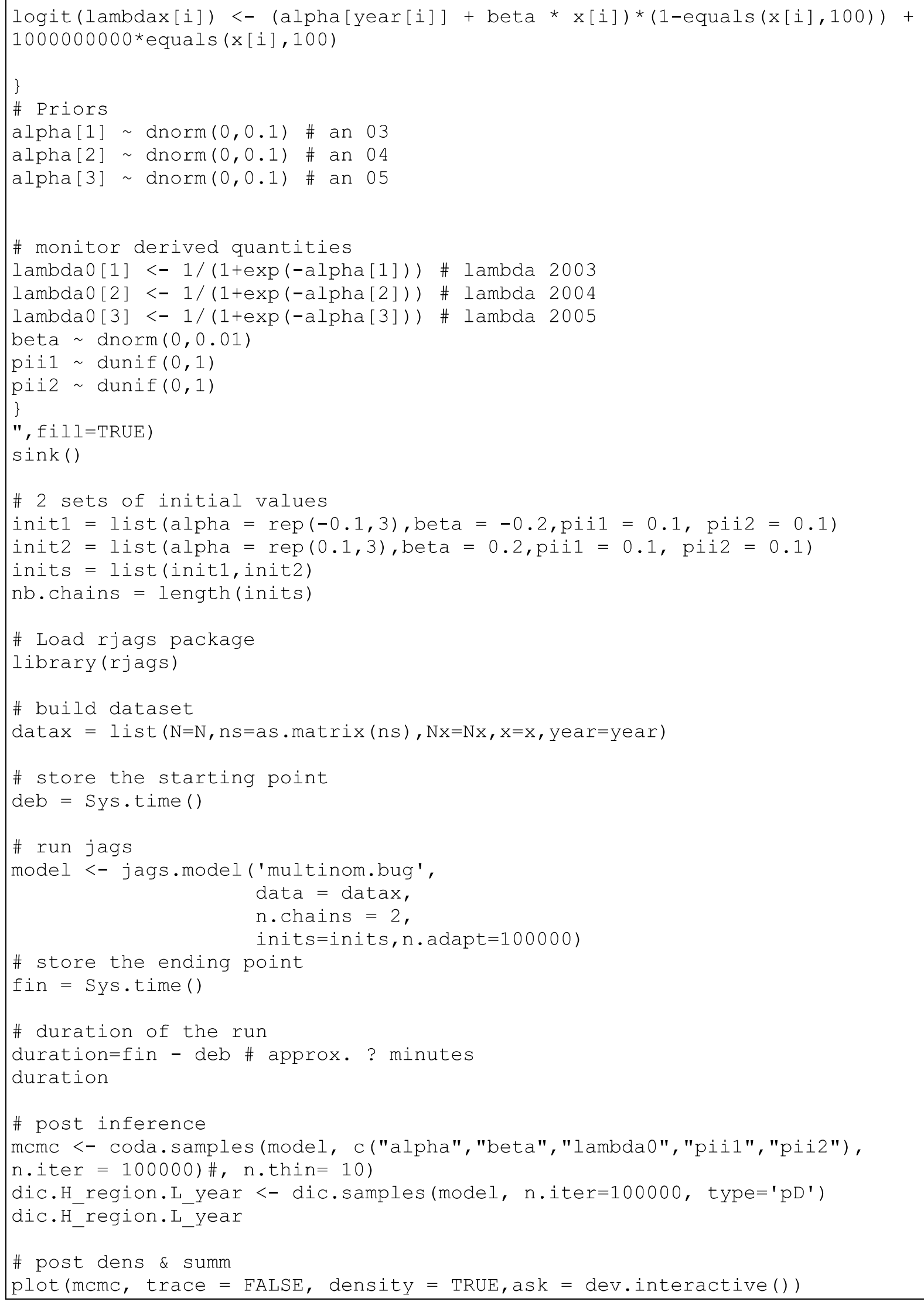




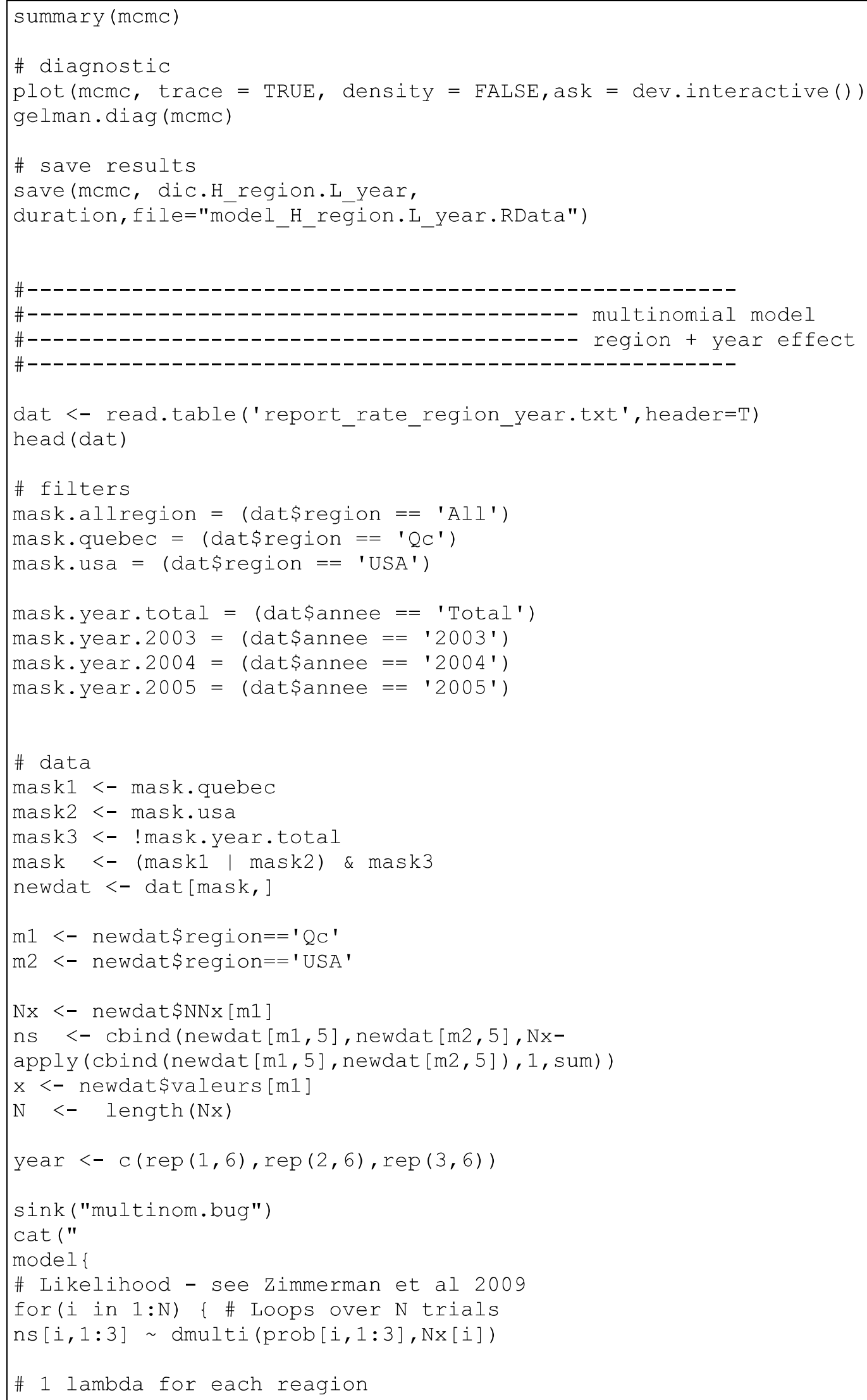




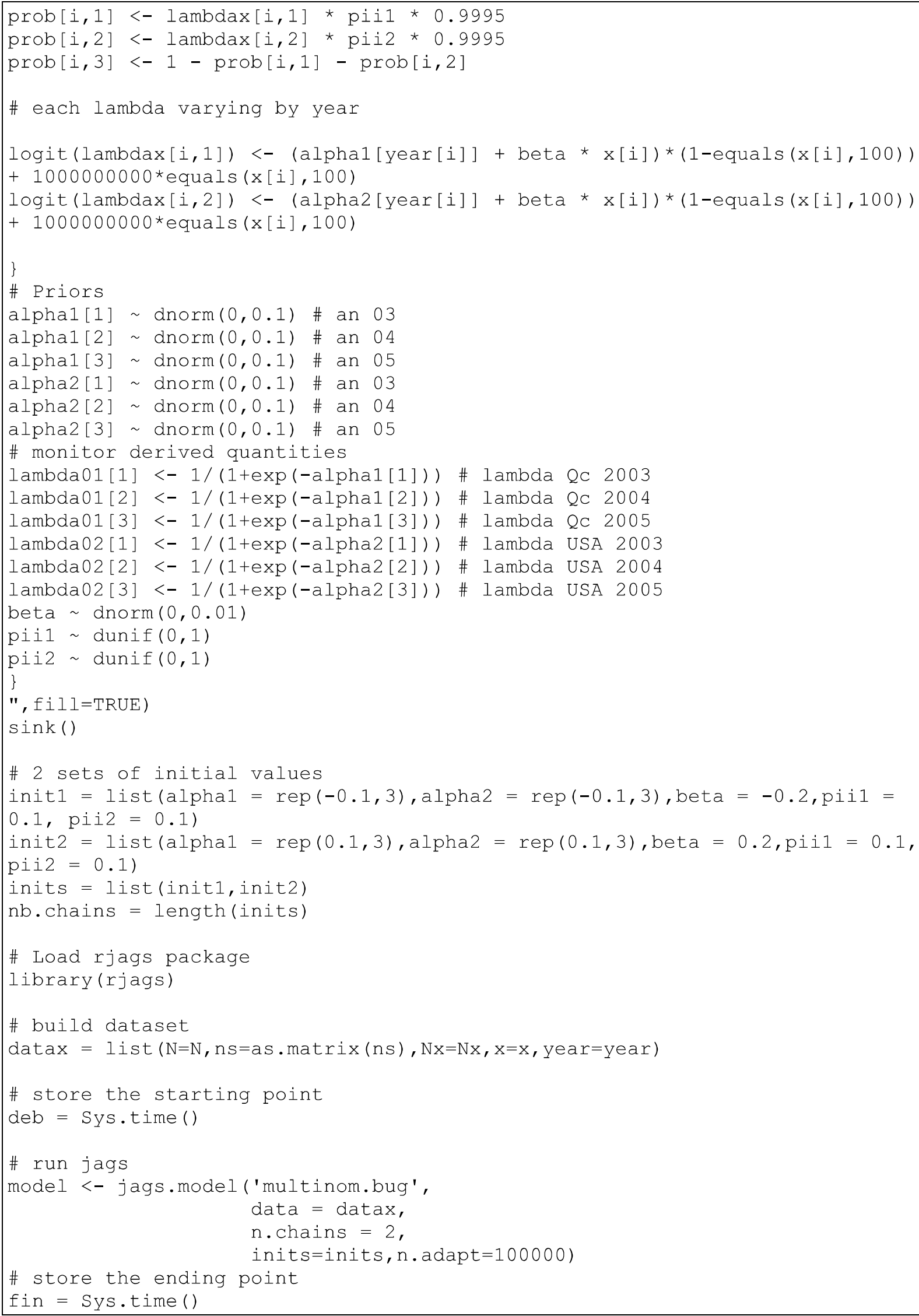


\# duration of the run

duration=fin - deb \# approx. ? minutes

duration

\# post inference

mcmc <- coda.samples (model,

c("alpha1","alpha2","beta","lambda01","lambda02","pii1","pii2"), n.iter = $100000) \#$, n.thin= 10)

dic.H_region.L_full <- dic.samples (model, n.iter=100000, type='pD')

dic.H_region.L_full

\# post dens \& summ

plot $(\mathrm{mcmc}$, trace $=$ FALSE, density $=$ TRUE, ask = dev.interactive( $)$ )

summary $(\mathrm{mcmc})$

\# diagnostic

plot (mcmc, trace = TRUE, density $=$ FALSE, ask = dev.interactive( $)$ )

gelman.diag $(\mathrm{mcmc})$

\# save results

save $(\mathrm{mcmc}$,

dic.H_region.L_full, duration,file="model_H_region.L_region.RData") 
Appendix 3. Survival $(S)$ and recovery $(f)$ rates estimations \pm SE from a band-recovery analysis for young and adult greater snow geese banded from 2002 to 2010 .

\begin{tabular}{llllll}
\hline \multirow{2}{*}{ Year } & \multicolumn{2}{l}{ Survival } & & & Recovery rate \\
\cline { 2 - 3 } \cline { 5 - 6 } & Young & Adult & & Young & Adult \\
\hline 2002 & $0.14 \pm 0.03$ & $0.65 \pm 0.04$ & & $0.040 \pm 0.007$ & $0.044 \pm 0.007$ \\
2003 & $0.30 \pm 0.07$ & $0.83 \pm 0.03$ & & $0.055 \pm 0.006$ & $0.038 \pm 0.004$ \\
2004 & $0.27 \pm 0.07$ & $0.86 \pm 0.03$ & & $0.052 \pm 0.008$ & $0.050 \pm 0.004$ \\
2005 & $0.29 \pm 0.07$ & $0.92 \pm 0.03$ & & $0.052 \pm 0.005$ & $0.047 \pm 0.003$ \\
2006 & $0.30 \pm 0.08$ & $0.84 \pm 0.03$ & & $0.050 \pm 0.005$ & $0.039 \pm 0.003$ \\
2007 & $0.40 \pm 0.11$ & $0.93 \pm 0.04$ & & $0.074 \pm 0.005$ & $0.037 \pm 0.003$ \\
2008 & $0.31 \pm 0.10$ & $0.78 \pm 0.04$ & & $0.070 \pm 0.006$ & $0.043 \pm 0.003$ \\
2009 & $0.53 \pm 0.19$ & $0.81 \pm 0.06$ & & $0.101 \pm 0.006$ & $0.042 \pm 0.003$ \\
2010 & $0.24 \pm 0.50$ & $0.90 \pm 0.16$ & & $0.100 \pm 0.006$ & $0.041 \pm 0.003$ \\
\hline
\end{tabular}

